\title{
VIII. Internationaler Congress für Hygiene und Demographie in Budapest 1894 unter dem
}

Allerhöchsten Protectorate Sr. k. u. k. apost. Majestät.

„Wie bekannt, findet der nächste VIII. internationale Congress für Hygiene und Demographie im Monate September des nächsten Jahres unter dem allerhöchsten Protectorate Seiner k. und k. apost. Majestät in Budapest statt. Die Vorarbeiten für den Congress nehmen einen sehr regen Fortgang, indem die Referate sowohl für die 19 hygienischen, als für die 7 demographischen Sectionen nicht nur festgestellt, sondern auch bereits die betreffenden Referenten des Auslandes um Uebernahme der Referate ersucht wurden und bereits jetzt von Seiten derselben vielfach Zusagen einliefen. Spätestens Anfang des künftigen Monats werden die weiteren Fragen, nach einzelnen Sectionen zusammengestellt, an alle Gelehrten des A uslandes versendet werden, so dass noch vor Beginn des Herbstes die Vorarbeiten für den wissenschaftlichen Theil des Congresses nahezu vollendet sein werden. In Verbindung mit dem Congresse findet auch eine hygienische Ausstellung statt, die insofern als Specialität gelten soll, als sie nicht als Industrieausstellung, sondern speciell als Illustrationsausstellung der auf dem Congresse zu baltenden Vorträge organisirt werden wird. Das detaillirte Programm dieser Ansstellung diurfte auch spätestens im Monat September bekannt gegeben werden.

Sobald das Executiv-Comité hinreichend orientirt sein wird, welche Gelehrten des Auslandes an dem Congresse theilnehmen werden, sollen die Ehrenpräsidien designirt werden.

Nach Schluss des Congresses werden mehrere Ausflüge vorbereitet, von denen namentlich derjenige nach der unteren Donau, zum eisernen Thor und nach Constantinopel eine grosse Anziehungskraft austiben dirfte."

Prof. C. Mïller m. p.

General-Secretair. 